\title{
Assessment of Risk Factors For Hypertention in A Rural Community in South-South Nigeria
}

\author{
${ }^{1}$ Ehimen, F.A., ${ }^{2}$ Abah S.O., ${ }^{1}$ Osagiede EF. ${ }^{2}$ Enahoro FO., \\ ${ }^{2}$ Adedudo S., ${ }^{2}$ Abudusalami BL \\ ${ }^{I}$ Department Of Community Medicine, Irrua Specialist Teaching Hospital, Irrua, Edo State, Nigeria \\ ${ }^{2}$ College of medicine, Ambrose Alli University, Ekpoma , Edo State, Nigeria
}

\begin{abstract}
Background: Hypertension is an important and often symptomless chronic condition yet implicated as an important cause of various cardiovascular complications; stroke, renal failure, blindness thereby reducing the quality of life and productivity of untreated hypertensives'. Risk factors for hypertension as revealed in literatures include the following- Age, Gender, family history of hypertension, race, high intake of alcohol, physical inactivity, smoking, obesity, high intake of saturated fat, diabetes mellitus etc.

Objectives of the study: To assess the prevalence, risk factors for hypertension amongst rural dweller in Etsako West LGA of Edo State. Additionally, the study sought to determine the relationship between basal metabolic index (BMI) and hypertension.

Methods: The descriptive cross sectional study was carried out using pre-tested self-administered questionnaires; it was distributed among 350 respondents who were recruited via multistage sampling technique. The blood pressure was measured in the sitting position using the left arm held at the level of the heart. Blood pressure (BP) was measured to the nearest $2 \mathrm{mmHg}$ on two occasions at an interval of 5 minute. The target populations were rural dwellers in South Ibia, Etsako West LGA of Edo State in South -south Nigeria. Variables were entered and analyzed was using SPSS software package. The association between various variables (risk factors, hypertention) were tested using appropriate test of statistics.

Results: Majority of the participants were within the age range of 18-27. Out of the 350 respondents 171 and 179 were male and female respectively. The prevalence of hypertension was $31.4 \%$ among the study participants. Majority of the respondents had normal body mass index (58.7\%), this was followed by pre-obese $(18.7 \%)$, obese (12.8\%) and underweight (9.9\%).

Conclusion: Early and prompt diagnosis of hypertension is key to prevention and control of its complications. This study emphasized the need to reduce weight through continuous exercise. Also, increased awareness of risk factors among rural dwellers will go a long way in reducing the burden of hypertension and its associated effects.
\end{abstract}

Keywords: Hypertension, Risk factors, rural community, Etsako West, Edo State

\section{Introduction}

Hypertension is a chronic non communicable disease, posing a major public health challenge to population in low socioeconomic and epidemiological transition. ${ }^{1}$ Currently, clinical criteria for diagnosing hypertension in a patient are generally based on the average of two or more seated blood pressure readings during each of two or more out-patient visits. ${ }^{2}$ Hypertension is an important and often symptomless chronic condition yet implicated as an important cause of various cardiovascular complications; stroke, renal failure, blindness thereby, reducing the quality of life and productivity of untreated hypertensives. ${ }^{1,2-4}$ Empirical and clinical studies had implicated the following among others as the risk factors for hypertension; Age, Gender, family history of hypertension, race, high intake of alcohol, physical inactivity, smoking, Obesity, high intake of saturated fat, diabetes mellitus.

Furthermore, epidemiological Studies had shown that the prevalence of hypertension is on the increase globally. ${ }^{3,4-5}$ World -wide, the prevalence of hypertension is about 1 billion and it accounts for 7.1 million death per year. ${ }^{4}$ A WHO statistics report of 2012 reveals that the world wide prevalence of hypertension is $29.2 \%$ for males and $24.8 \%$ for females. ${ }^{6}$ Hypertension was thought to be rare in rural communities; however, hypertension is now shown to be on the increase in rural as well as in urban communities in Nigeria. ${ }^{7,8}$ In 2010, a prevalence rate of 32.8\% was reported from a study in a rural and semi urban population in Enugu, Nigeria. ${ }^{9}$. Also, in 2010 another cross-sectional community based survey reported a prevalence of $20.8 \%$ in the rural community of Egbeda, southwest Nigeria while the prevalence in Ipetumodu, Osun State, Nigeria, was $26.4 \%$ for mild hypertension (systolic BP 140/90 $\mathrm{mmHg}$ ) and 11.8\% for moderate hypertension (systolic BP 160/100 $\mathrm{mmHg}$ ) and that in semi-urban Ile-Ife was $36.6 \% .^{10}$ 
As mentioned earlier, rural areas in Edo State and Nigeria are in transitional phase. This increases the risk of conditions like hypertension in rural areas. However, anecdotal reports have demonstrated the scarcity of these studies in rural areas of developing countries. Against this background, this study was undertaken to study the prevalence and risk factors for hypertension amongst rural dwellers.

\section{Material And Methods}

The community based cross sectional survey was conducted among individuals in a rural area located in South Ibie, Etsako West Local Government Area of Edo state.

\section{Inclusion Criteria}

Only individuals who were 18 years and above; not suffering from other ailments, not on treatment for hypertension and who gave consent for interview and checking of their blood pressure and physical examination were included into the study.

\section{Exclusion Criteria}

Known hypertensive's on medication, with other ailment that might affect BP and pregnant women were excluded

Sample size and Sampling Technique

A minimum sample size of 350 was calculated based on the reported prevalence of hypertension rate in Edo state. ${ }^{11}$ Multi stage sampling technique was used in recruiting the participants into the study.

\section{Data Collection/Analysis}

Data were collected using a pre-tested interviewer administered questionnaire to elicit sociodemographic information including age, gender, smoking and alcohol consumption. Medical histories such as prior knowledge of blood pressure status, family history of hypertension, use of drugs were also elicited by the questionnaire. Anthropometric measurement (height and weight) and blood pressure measurements were also carried out with standard equipments and recorded in the questionnaire. The BMI was calculated and recorded also in the questionnaire. The responses were collected, collated and analysed with SPSS 16. Differences in demographic characteristics between participants were analysed using the Chi-square test. The student t-test was also used to compare the age distribution of males and females. A p-value of less than $5 \%$ was considered statistically significant.

\section{Ethical considerations}

Ethical approval was obtained from the Ambrose Alli University ethics committee

\section{Demographic characteristics}

\section{Results}

A total of 366 questionnaires were distributed among the respondents but only 350 responded, given a response rate of $96 \%$. Majority of the respondents (35.2\%) were within the age of 18-27 year while ages 28-37, $38-47,48-57,58-67$ and 68 years and above account for $18.8 \%, 17.1 \%, 13.0 \%, 5.5 \%$ and $10.4 \%$ respectively. Regarding gender, the female respondents $(51.8 \%)$ were more than male respondents $(48.2 \%)$. Regarding ethnicity, most $(97.1 \%)$ of the respondents were Etsako. Concerning level of education, $44.0 \%$ had primary level of education while $28.9 \%, 20.9 \%$ and $6.3 \%$ had secondary, tertiary, and none respectively. Regarding occupation, most $(30.2 \%)$ were farmers (see Table 1$)$.

\section{Prevalence of hypertension}

The overall prevalence of hypertension in the study was $31.4 \%$ (see Figure 1). Steady increase in the prevalence of hypertension along increasing age groups was noticed in this study. This association was found to be highly significant $(\mathrm{P}<0.00001)$ see Table 2 . Thirty four percent of those with a positive family history of hypertension were hypertensive compared with $65.79 \%$ of those who are normotensive but with a family history of hypertension. Also, $33.33 \%$ of those with no family history of hypertension where hypertensive compared to $66.67 \%$ of those without a family history of hypertension are normotensive ( see Table 3 ). The prevalence of hypertension among those who consumed alcohol is $36.36 \%$ while the prevalence of hypertension among those who do not consume alcohol is $29.28 \%$. $\mathrm{OR}=1.38$ but this was not statistically significant (Table 4). Also, the prevalence of hypertension was higher among smokers (36.54\%) compared to non smokers (31.27).the odds of smokers developing hypertension was 1.27 . (see Table 5).

\section{Relationship between BMI and Hypertension}

Table 6- it can be inferred that the prevalence of hypertension increases with increasing BMI. This relationship was found to be significant, $\mathrm{P}=0.00102$ 
Table 1: Socio-Demographic Characteristics Of Respondents

\begin{tabular}{|c|c|c|}
\hline Variables & Frequency & Percent (\%) \\
\hline $\begin{array}{l}\text { AGE GROUP (YEARS) } \\
18-27\end{array}$ & 122 & 35.2 \\
\hline $28-37$ & 65 & 18.8 \\
\hline $38-47$ & 59 & 17.1 \\
\hline & 45 & 13.0 \\
\hline $58-67$ & 19 & 5.5 \\
\hline$\geq 68$ & 36 & 10.4 \\
\hline $\begin{array}{l}\text { GENDER } \\
\text { Male }\end{array}$ & 171 & 48.9 \\
\hline Female & 179 & 51.1 \\
\hline $\begin{array}{l}\text { TRIBE } \\
\text { Etsako }\end{array}$ & 340 & 97.1 \\
\hline Idoma & 4 & 1.1 \\
\hline Others & 6 & 1.8 \\
\hline $\begin{array}{l}\text { MARITAL STATUS } \\
\text { Single }\end{array}$ & 75 & 21.6 \\
\hline Married & 235 & 67.5 \\
\hline Divorced & 2 & .6 \\
\hline Widow & 36 & 10.3 \\
\hline $\begin{array}{l}\text { LEVEL OF EDUCATION } \\
\text { Primary }\end{array}$ & 154 & 44.0 \\
\hline Secondary & 101 & 28.9 \\
\hline Tertiary & 73 & 20.9 \\
\hline None & 22 & 6.3 \\
\hline $\begin{array}{l}\text { OCCUPATION } \\
\text { Farmer }\end{array}$ & 104 & 30.2 \\
\hline Trader & 76 & 22.1 \\
\hline Student & 81 & 23.5 \\
\hline Artisan & 59 & 17.2 \\
\hline Others & 24 & 7.0 \\
\hline $\begin{array}{l}\text { RELIGION } \\
\text { Christian }\end{array}$ & 107 & 30.9 \\
\hline Muslim & 232 & 67.1 \\
\hline Others & 7 & 2.0 \\
\hline
\end{tabular}

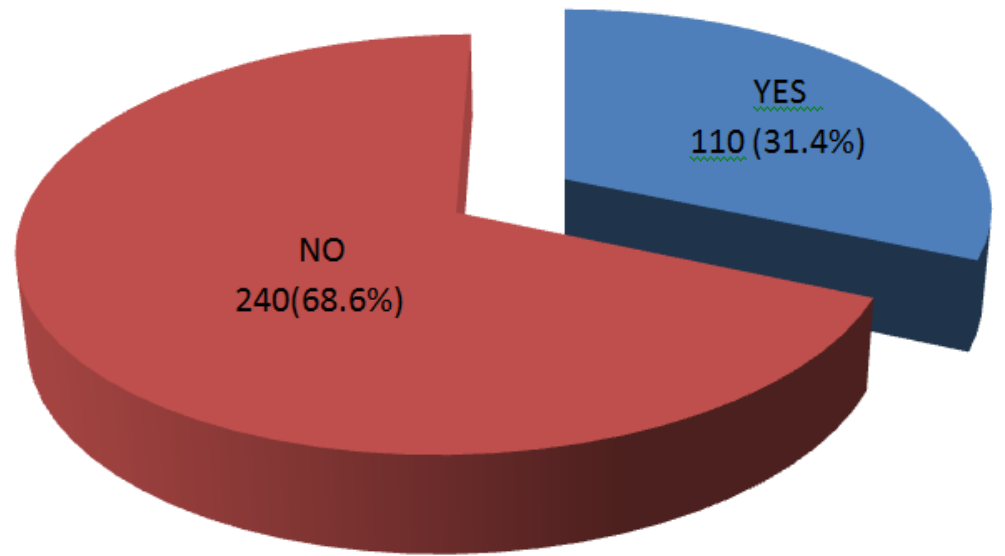

Fig 1: The Prevalence Of Hypertension

Table 2: Distribution Of Subjects Based On Blood Pressure And Age

\begin{tabular}{|c|c|c|c|c|}
\hline \multicolumn{2}{|c|}{ Hypertensive } & \multicolumn{3}{|c|}{ Normotensive } \\
\hline n & $(\%)$ & $\mathbf{n}$ & $(\%)$ & Test /p-value \\
\hline $18-27$ & 18 & $(14.8)$ & 104 & $(85.2)$ \\
\hline $28-37$ & 16 & $(24.6)$ & 49 & $(75.4)$ \\
\hline $38-47$ & 20 & $(33.9)$ & 39 & $\mathrm{X}^{2}=64.546208 \mathrm{p}=0.00001$ \\
\hline $48-57$ & 16 & (35.6) & 29 & (64.4) \\
\hline $58-67$ & 17 & $(89.5)$ & 2 & $(10.5)$ \\
\hline$\geq 68$ & 23 & $(63.9)$ & 13 & $(36.1)$ \\
\hline
\end{tabular}


Table 3: Distribution Of Subjects According To Blood Pressure-Status And Family History

\begin{tabular}{|l|l|l|l|l|ll|}
\hline \multicolumn{2}{|c|}{} & \multicolumn{4}{|l|}{ Hypertensive } & \multicolumn{2}{l|}{ Normotensive } & Test/p-value \\
\cline { 3 - 7 } \multicolumn{2}{|c|}{} & n & $(\boldsymbol{\%})$ & n & $(\%)$ & \\
\hline \multirow{2}{*}{ Yes } & 13 & $(34.21)$ & 25 & $(65.79)$ & $\mathrm{X}^{2}=0.1544 \mathrm{p}=0.925673$ \\
\cline { 2 - 7 } & No & 23 & $(33.33)$ & 46 & $(66.67)$ & \\
\cline { 2 - 6 } & I don't know & 56 & $(31.46)$ & 122 & $(68.54)$ & \\
\hline
\end{tabular}

Table 4: Distribution Of Subjects According To Blood Pressure-Status And Alcohol Consumption

\begin{tabular}{|c|c|c|c|c|c|}
\hline & \multicolumn{2}{|c|}{ Hypertensive } & \multicolumn{2}{|c|}{ Normotensive } & \\
\hline & $\mathbf{n}$ & $(\%)$ & $\mathbf{n}$ & $(\%)$ & Test/p-value \\
\hline Yes & 32 & (36.36) & 56 & $(63.63)$ & \\
\hline No & 65 & $(29.28)$ & 157 & $(70.72)$ & $X^{2}=1.471116 p$-value $=0.225$ \\
\hline
\end{tabular}

Table 5: Distribution Of Subjects According To Blood Pressure-Status And Smoking

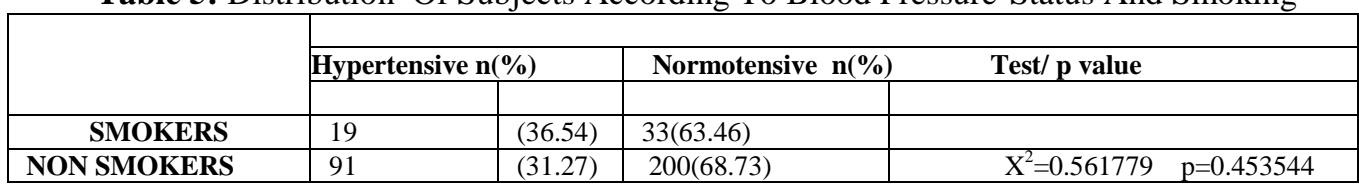

Table 6: Distribution Of Subjects According To Blood Pressure-Status And Bmi

\begin{tabular}{|c|c|c|c|c|c|}
\hline \multirow{3}{*}{\multicolumn{2}{|c|}{$\begin{array}{l}\text { BMI } \\
\left(\mathbf{K g} / \mathbf{m}^{2}\right)\end{array}$}} & \multirow{2}{*}{\multicolumn{2}{|c|}{ Hypertensive }} & \multirow[b]{2}{*}{ Normotensive } & \multirow{3}{*}{ Test/p -value } \\
\hline & & & & & \\
\hline & & $\mathbf{n}$ & $(\%)$ & $\mathbf{n}$ & \\
\hline & $<18.5$ & 5 & $(14.71)$ & 29 & $(85.29)$ \\
\hline & $18.5-24.9$ & 58 & (29) & 142 & $(71)$ \\
\hline & $25.0-29.9$ & 21 & $(32.81)$ & 43 & $\mathrm{X}^{2}=20.5, \mathrm{p}=0.001021$ \\
\hline & $30.0-34.9$ & 19 & $(55.88)$ & 15 & $(44.12)$ \\
\hline & $35.0-39.9$ & 6 & $(60)$ & 4 & $(40)$ \\
\hline & $>40.0$ & 0 & $(0.0)$ & 0 & $(0.0)$ \\
\hline
\end{tabular}

\section{Discussion}

Following the JNC-7 and WHO definition of hypertension, the prevalence of hypertension in this study was $31.4 \%$. The figure is higher compared to was reported among the Ibibio/Anangs Efiks and the Obolos where the prevalence of hypertension was less than $25 \% .^{12}$ The prevalence in this present study is also higher than the prevalence reported in other previous works. ${ }^{13,14,15,16,17}$ However, the prevalence in this study was lower compared to other studies.. ${ }^{11,18}$ Furthermore, a work done in Uganda reported a prevalence of $30.4 \%$ which is comparable with this study. ${ }^{19}$ Our findings therefore confirm the growing concern about hypertension as a public health problem in rural community in Nigeria.

This study showed that prevalence of hypertension increases with advancing age. This association was found to be highly significant $(\mathrm{P}<0.00001)$. The finding was consistent with the reports from earlier studies where increasing prevalence rate of hypertension is associated with increasing age. ${ }^{14,15,20-22}$. Hence, this study showed that increasing age is a risk factor for developing hypertension.Furthermore, it was revealed that the prevalence of hypertension was higher among those with positive family history of hypertension, smoking and drinking of alcohols. However, these relationships were not statistically significant. However, our findings were similar to those reported in other studies. ${ }^{19,}{ }^{23-25}$ Majority of respondents from this work had normal body mass index. This compares with a work carried out in Osun state which reported a that $19.6 \%$ of their respondents had a BMI of 25-29.9, (pre-obese), while $11.5 \%$ of the respondents had a BMI of 30 and above. ${ }^{13}$ Our study showed that the prevalence of hypertension increases with increasing BMI. This was found to statistically significant $(\mathrm{p}=0.00102)$. This was comparable with the study done in Nigeria, which reported a significant association between hypertension and obesity as defined by BMI. (OR 2.12, 95\% CI 1.26-3.54, P=0.004). ${ }^{20}$ This findings was further buttressed by a study conducted in three urban and rural communities in Ethiopia, Indonesia and Vietnam where it was stated that hypertension increases with increase BMI quintile. ${ }^{26}$

\section{Conclusion/Recommendations}

The prevalence of hypertension in our study was $31.4 \%$. There was a significant relationship between increasing age, BMI and hypertension. Also, the study revealed that there is high prevalence of hypertension among individuals with family history of hypertension and those smoking and taking alcohol, however, these relationships were not statistically significant. Based on the aforementioned, there is need to have a dedicated Local Government Health program focusing solely on prevention of hypertension in rural communities and these program should include health education, screening and treatment of hypertension. More studies are required to be conducted among rural dwellers to assess other key determinants and preventive measures of hypertension. 


\section{Conflict Of Interest}

None identified in this study

\section{Aknowledgement}

The authors acknowledge the invaluable assistance of the department of Community Medicine, ISTH and Ambrose Alli University Edo State, Nigeria.

\section{References}

[1]. Park K, Park's Textbook of Preventive and Social Medicine. $20^{\mathrm{TH}}$ edition, M/s Banarasidas Bhanot Publishers, 2005; Chapter 6: Hypertension; p. 323-327

[2]. Theodore A. Kotchen. Hypertensive vascular disease. In Anthony S.et.al (sseds). Harrison Principle of Internal Medicine.17 Ed, United States of America, Mc.Graw Hill Companies, Inc, 2008.

[3]. Kearney PM, Whelton M, Reynolds K, Munter P, Wheaton PK, He J. Global burden of hypertension: analysis of worldwide data. Lancet . 2005; 365: 217-23.

[4]. WHO. Integrated management of cardiovascular risk: report of a WHO meeting, Geneva WHO,2002:9 -12

[5]. World Health Organization. Prospects of Research, on non-communicable diseases in the African sub-region.2008 Available at http/www.int/dpm/rpc/publications/ncdwokk.pdf Accessed $2^{\text {nd }}$ March, 2016

[6]. WHO. Integrated management of cardiovascular risk: report of a WHO meeting, Geneva WHO,2012:2 -34

[7]. $\quad$ Pobee J O, Larb E B, Belchor D W, Wurapa F K, Dodu S R, (Blood Trop Med Hyg. 1977. 71; 66-72

[8]. Cooper RS, Rotimi CN, Karfman JS, (1998). Hypertension Treatment and Control in Sub Saharan Africa: the Epidemiology basis for Policy. BMJ. 316: 614-617

[9]. Ulasi II, Ijeoma CK , Onodugo OD (2010). A community based study of hypertension and cardiometabolic syndrome in a semi urban and rural communities in Nigeria. BMC Health Service Research. 10-71

[10]. Oladapo OO, Salako L, Sodiq O, Shoyinka A, Adedapo K, Falase A O. A prevalence of Cardiometabolic risk factors among a rural Yoruba south- western Nigeria populations; a population survey. Cardiovasc J Apr.2010;21:26-31

[11]. Peter Okokhere, Irene Akhidenor, (2003): Hypertension in a rural Esan community. A preliminary report; Annals of Medical Research. June 2013;14:111-117

[12]. Joseph J Andy, Udeme Ekrikpo. Prevalence and correlations of hypertension among the Ibibio/Amangs, Efiks, Obolos; a cross sectional survey in rural south south Nigeria. Ethnicity and Disease. 2012;12:235 - 339

[13]. E O Asekun - Olarinmoye, P.O Akinwusi, W OAdebimpe, M A Isawumi, M B Hassin, O A Olowe et al. Prevalence of hypertension in a rural adult population of Osun state, southwestern Nigeria. Dove press Journal of general medicine. 2013:6 -20

[14]. Chizindu Akubudike. A, Pedro Chimezie, Osaretin J. O. Hypertension in a rural community in Rivers state Nigeria: Prevalence and risk factors. The Nigerian Health Journal. 2013;13(1):18 - 25

[15]. Adediran Olufemi Sola, Okpara Ihunanya Chinyere, Adeniyi Olasupo Stephen, Jimoh Ahmed Kayode; Hypetrtension prevalence in urban and rural area of Nigeria. Journal of medicine and medical science. 2013;4: $149-154$,

[16]. Friday S, Wokoma, Datonye.D Alasia. Blood pressure pattern in Barako- a rural community in Rivers state Nigeria. The Nigerian Health Journal. 2011;11:8 - 13

[17]. Arthur C O, Mary M, Seye B. prevalence of hypertension in Kegbara - Dara a rural community in Niger Delta region of Nigeria. Ethnicity and Disease.2012;22:340-346

[18]. Mbah B. O, Eme P.E, Ezeji J. prevalence and risk factors of hypertension among middle aged adults in Ahiazu Mbaise local government.IJBAS- IJENS. 2013;13(1):26-30

[19]. Wamala JF, Karyabakabo Z, Ndungustse D and Guwatudde D. prevalence factors associated with Hypertension in Rukungiri District, Uganda- A community- based study. Afr Health Sci. 2009; 9(3): 153-160.

[20]. Ojomu Funke, Kuranga Sulieman Ibrahim. Blood pressure and BMI among Jos University Teaching Hospital staff. Transnational journal of science and Technology. 2013;3(9):1-5t

[21]. Hemna S, Qudsia A, Amir O, Jaweed U, Raza R, Tabinda A. Risk factors assessment for hypertension in a squatter settlement of Karachi in Pakistan. J. Park Medical Association. 2005(9):390 - 392

[22]. Sathya P.M, Attayuru P.S, Vivek B, Nagalla B, Mendu V, Kasturi S.P; association of hypertension with risk factors and related behavior among the aboriginal Nicobarese tribe living in Car Nicobar Island. Indian J.Med, Res. 2011;13: 287 -293

[23]. Sumeet Gupta, Bimal K. Agrawal, Prabodh K Sehajpal, Rajesh K Goel. Prevalence and Prediction of Essential Hypertension in the rural population of Haryana, India. A hospital based study. Journal of rural and tropical public health.2011;10:29-34

[24]. Alexandros Briasoulis, Vikram Agarwal, and Franz H.Messerli. Alcohol consumption and the risk of hypertension in men and women: A systematic review and meta-analysis. Journal of clinical Hypertension.2012;14(11):2-22

[25]. Myoung Kyun Son, Association between alcohol consumption and hypertension. Journal of Korean Society of hypertension 2011; 17(2):65-73

[26]. Tesfaye F, Nawi NG, Van M, Byass BP, Behane Y, Bonitta R, Wall S. Association between BMI and blood pressure across three populations in Africa and Asia. Journal of human hypertension. 2007; 21: 28 - 37 